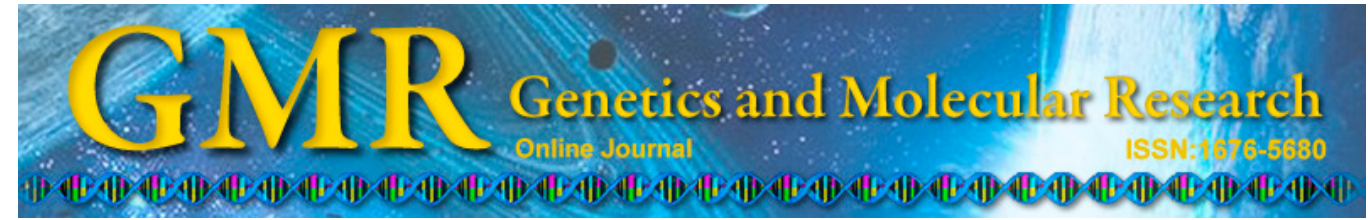

\title{
Multidrug resistance gene and its relationship to ulcerative colitis and immune status of ulcerative colitis
}

\author{
Y.J. Zhang ${ }^{1}$, J.J. Xu1 ${ }^{1}$ P. Wang ${ }^{2}$ and J.L. Wang ${ }^{1}$ \\ ${ }^{1}$ Department of Gastroenterology, \\ The First Affiliated Hospital of Henan University of Science and Technology, \\ Luoyang, Henan Province, China \\ ${ }^{2}$ School of Public Health, Henan University of Technology, Luoyang, \\ Henan Province, China \\ Corresponding author: Y.J. Zhang \\ E-mail: zyjhkdyfy1268@163.com
}

Genet. Mol. Res. 13 (4): 10837-10851 (2014)

Received January 14, 2014

Accepted March 3, 2014

Published December 19, 2014

DOI http://dx.doi.org/10.4238/2014.December.19.5

\begin{abstract}
We examined the relationship among the multidrug resistance $(M D R 1)$ gene product $\mathrm{P}$-glycoprotein (P-gp), ulcerative colitis, and immune status under ulcerative colitis. MDR1 P-gp expression and interleukin-8 levels in ulcerative colitis were determined using immunohistochemistry and a double-antibody sandwich avidinbiotin complex-enzyme-linked immunosorbent assay, respectively. Nitric oxide content and nitric oxide synthase activity in the colonic mucosa were determined using a colorimetric method; $\mathrm{CD} 4^{+}$and $\mathrm{CD} 25^{+}$ $\mathrm{T}$ cell subset percentages in the peripheral blood were determined by flow cytometry. The positive expression rate of P-gp in patients with ulcerative colitis $(17.4 \%)$ was significantly lower than that in the control group (31.4\%). The expression rate decreased to 10.1, 9.2, and $8.3 \%$ after 12,18 , and 24 months of treatment, respectively, which were significantly lower than the expression rate before treatment (17.4\%). P-gp expression levels during the remission phase and active phase
\end{abstract}


of ulcerative colitis were 15.2 and $17.1 \%$, respectively, which were significantly lower than that in normal controls $(31.4 \%)$. Compared with P-gp-negative patients, nitric oxide content, nitric oxide synthase activity, and interleukin-8 levels were significantly higher in P-gppositive patients with moderately active, severely active, early onset, chronic relapsing, chronic persistent, and acute fulminant ulcerative colitis. $\mathrm{CD} 4^{+}$and $\mathrm{CD} 25^{+} \mathrm{T}$ cell subsets were significantly lower in the peripheral blood of patients with severely active and acute fulminant ulcerative colitis than in control subjects. Expression of the multidrug resistance gene and its product P-gp was observed in normal colon tissues and may be closely related to ulcerative colitis.

Key words: Colitis; Drug resistance; Immune status; NOS activity; IL-8; $\mathrm{CD}^{+}$and $\mathrm{CD} 25^{+} \mathrm{T}$ cells

\section{INTRODUCTION}

Recent studies have indicated that the multidrug resistance gene (MDR1) expression product, $\mathrm{P}$-glycoprotein (P-gp), is related to the pathogenesis of ulcerative colitis (UC) (Mendoza et al., 2007). Potocnik et al. (2004) suggested that P-gp expression and activity are lower in the peripheral blood, colonic tissue lamina propria, and colonic intraepithelial lymphocytes in UC patients compared to control patients. Farrell and Kelleher (2003) demonstrated that inflammatory bowel diseases, including Crohn's disease and UC, are resistant to glucocorticoid and immunosuppressant drugs, and that patients requiring surgical treatment have higher P-gp levels in peripheral lymphocytes and the colonic epithelium compared to drug-sensitive and normal control groups. These results differ from those reported by Potocnik et al. (2004).

Studies have focused on the pathogenesis and immunological mechanisms of UC. Studies examining the histopathology and clinical characteristics of UC and the effectiveness of immunosuppressive therapy indicate that the immune system plays an important role in UC development (Spahn and Kucharzlk, 2004).

The immune system is an expansive network that requires coordination and interaction between its various parts to maintain the body immune response and immune tolerance. Disruption of any part of the immune system can lead to an immune imbalance (Forchielli and Walker, 2005). An abnormal response of the body immune system to normal intestinal flora plays a major role in the pathogenesis of UC, which involves the entire immune response (Thompson-Chagoyán et al., 2005). Multidrug resistant (MDRla) genes are expressed on both immune and non-immune cell surfaces and have multiple functions (Chandran et al., 2003). Dommels et al. (2007), using FVB wild-type and FVB multi-drug resistance gene knockout $\left(M D R 1 a^{-/}\right)$mice, observed P-gp in colitis and determined the humoral and cellular immune function in a UC group and non-UC group of $M D R 1 a^{-/ 2}$ mice. A study of the clinical features, pathology, and immunohistochemistry of UC in $124 M D R 1 a^{-/-}$mice demonstrated that 24 mice (21\%) had diarrhea, weight loss, and similar pathology, which was similar to the symptoms observed in humans with $\mathrm{UC}$, as well as $\mathrm{CD}^{+} \mathrm{T}$ lymphocyte and B lymphocyte infiltration in the colon mucosa lamina propria. Serum antibody and cytotoxic T lymphocyte function in $M D R 1 a^{-/}$mice without UC were similar to those in wild-type FVB mice. These results indicate that colitis can occur in mice lacking MDRla; however, the pathogenesis of 
colitis is unrelated to the systemic immune response, and is possibly due to an abnormal local colonic epithelial cell barrier. Asari et al. (2010) confirmed that MDRla is the only P-gp gene expressed in mouse intestinal epithelial cells and intestinal lymphocytes and established an $M D R 1 a^{-/}$mouse model of inflammatory bowel disease.

In this study, we used immunohistochemical methods to detect the UC MDR1 gene product P-gp, the double-antibody sandwich avidin-biotin complex-enzyme-linked immunosorbent assay (ELISA) method to measure serum interleukin (IL)-8 levels, colorimetry to measure nitric oxide (NO) content and nitric oxide synthase (NOS) activity in the colonic mucosa, and flow cytometry to determine peripheral blood $\mathrm{CD} 4^{+}$and $\mathrm{CD} 25^{+} \mathrm{T}$ cell subset percentages. The purpose of this study was to determine the relationship between the MDRI product P-gp and the clinical characteristics of UC in humans. We also examined the relationship with the immune status of UC patients to provide a theoretical and practical basis for preventing and managing UC.

\section{MATERIAL AND METHODS}

\section{Patients and controls}

Patients were selected from outpatients and inpatients treated in the 3 affiliated hospitals of Henan University of Technology, China, from March 2007 to December 2012. Of the 109 patients, 68 were male and 41 were female aged 17-70 years, with an average age of 41.2 years. In the control group, electronic colonoscopy samples were acquired from 15 patients without intestinal symptoms who were confirmed to have normal pathology, no history of irritable bowel syndrome, past history of UC, and no drug allergies. Another 20 normal surgical samples of bowel tissue were obtained from patients without inflammatory bowel disease. Of these 35 samples, 19 were from males and 16 were from females aged 19-68 years, with an average age of 39.4 years. Study subjects were followed-up for 24 months with a starting time indicated by the treatment time or discharge time. The last patient included was in December 2010 and was followed-up until December 2012. Patients were divided into groups, including a no-drug group and groups that had been treated with oral aminosalicylate drugs, oral or intravenous corticosteroids, oral or intravenous corticosteroids and immunosuppressive agents, topical application of sulfasalazine, 5-aminosalicylic acid, glucocorticoids, and traditional Chinese medicine.

The study protocol was approved by the Ethics Committee of Henan University of Technology. Informed consent to participate in the study and undergo surgery was obtained from all patients.

\section{Pathological diagnoses}

All endoscopic biopsy and resection specimens were evaluated by at least 2 experienced pathologists. In cases where there was a disagreement, a third pathologist reviewed the case and gave a final diagnosis.

\section{Clinical severity classifications}

In accordance with the UC treatment guidelines of the American Gastroenterological Association (Arnold et al., 1998), disease severity was graded as mild, moderate, or severe. 


\section{Endoscopic grading standards}

According to Baron's improved endoscopic grading standards of UC (Saverymuttu et al., 1986), the following grades were used: grade 0 , grade I, grade II, grade III, and grade IV.

\section{Immunohistochemical staining}

The streptavidin-peroxidase method was used and antigen retrieval was required before P-gp measurement. As a negative control, normal serum was used rather than primary antibody. The remaining steps were the same. The P-gp-positive control was the serum of a colon cancer patient (Figures 1 and 2).

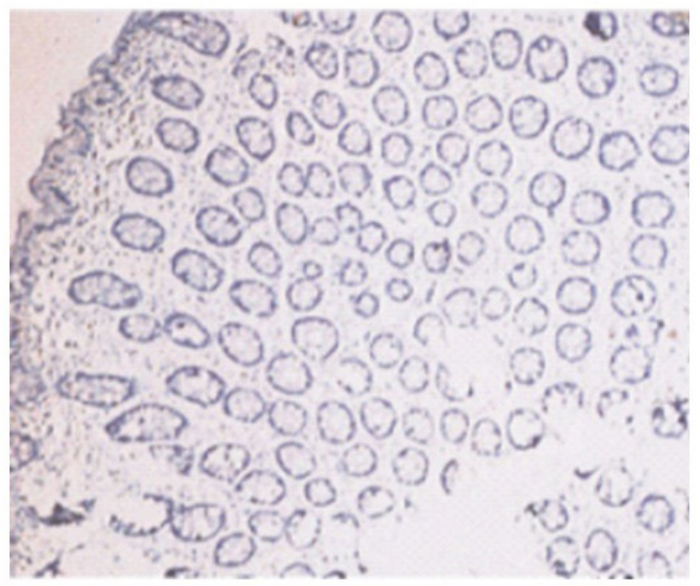

Figure 1. Negative expression of P-gp in colonic mucosa. SP method 400X.

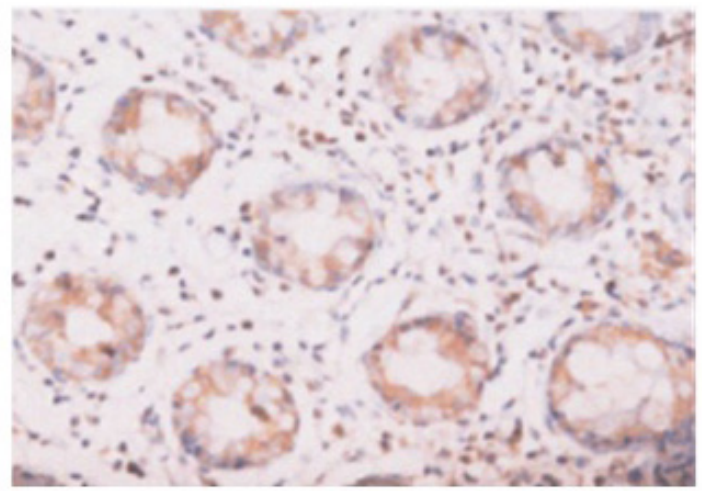

Figure 2. Positive expression of P-gp in the interstitial lymphocyte membrane and nucleus of colonic epithelial cells. P-gp-positive particles were mainly located in the lamina propria of the colonic mucosa and intestinal epithelial tissue and are shown as clear brown color in the cell membrane and cytoplasm. SP method 400X. 


\section{Determination of serum IL-8 levels}

The double antibody sandwich avidin-biotin complex ELISA was used to determine serum IL-8 levels.

\section{NO content and NOS activity in colonic mucosa}

Serum levels of NO were measured using the nitrate reductase assay. NOS activity was assessed by measuring the amount of NO from L-arginine catalyzed by NOS per unit time. By measuring total NOS activity and inducible NOS (iNOS) activity without $\mathrm{CaCl}_{2}$ in the reaction solution, the $\mathrm{Ca}^{2+}$-dependent catalytic arginine and structural activity was calculated by subtracting iNOS activity from total NOS activity. The Biuret method was used to determine total protein content in the homogenates. $\mathrm{NO}$ concentration was measured as $\mu \mathrm{mol} / \mathrm{g}$ and NOS activity as $\mathrm{U} / \mathrm{mg}$.

\section{Peripheral blood $\mathrm{CD}^{+}$and $\mathrm{CD}^{+} 5^{+} \mathrm{T}$ cell subsets}

Flow cytometry was used to determine peripheral blood $\mathrm{CD} 4^{+}$and $\mathrm{CD} 25^{+} \mathrm{T}$ cell subsets.

\section{Statistics}

The SPSS 10.0 statistical package was used for data entry and statistical analysis (SPSS, Inc.; Chicago, IL, USA). Count data are reported as a percentage, and 2 sets of data were compared using the Student $t$-test. The P-gp-positive expression rate in each group was compared using the $\chi^{2}$ test. A P value of $<0.05$ was considered to be significantly different between 2 groups.

\section{RESULTS}

\section{P-gp and duration of UC}

There were 109 cases of UC before and after treatment and 35 normal controls included in this study. Compared to the control group, the P-gp-positive rate was significantly lower in patients with $\mathrm{UC}$ before and after $6,12,18$, and 24 months of treatment $(\mathrm{P}<0.05)$. In UC patients, the P-gp-positive rate was significantly lower after 12, 18, and 24 months of treatment $(\mathrm{P}<$ $0.05)$; however, there was no significant change after 6 months of treatment $(\mathrm{P}>0.05)$ (Table 1).

\begin{tabular}{|c|c|c|c|c|}
\hline Duration of UC & $\mathrm{N}$ & Positive $(\mathrm{N})$ & Negative $(\mathrm{N})$ & Positive rate (\%) \\
\hline Control & 35 & 11 & 24 & 31.4 \\
\hline Before treatment & 109 & 19 & 90 & $17.4^{\mathrm{a}}$ \\
\hline \multicolumn{5}{|l|}{ After treatment } \\
\hline 6 months & 109 & 18 & 91 & $16.5^{\mathrm{ac}}$ \\
\hline 12 months & 109 & 11 & 98 & $10 . .^{\text {abd }}$ \\
\hline 18 months & 109 & 10 & 99 & $9.2^{2 \mathrm{abd}}$ \\
\hline 24 months & 109 & 9 & 100 & $8.3^{\text {abd }}$ \\
\hline
\end{tabular}




\section{P-gp and clinical type of UC}

The clinical types of UC were divided into early onset, chronic relapsing, chronic persistent, and acute fulminant. Positive P-gp expression in all clinical types was significantly lower than in control subjects $(\mathrm{P}<0.05)$; there was no significant difference between the early onset type and chronic relapsing or chronic persistent types $(\mathrm{P}>0.05)$. The $\mathrm{P}$-gp-positive expression rate in the acute fulminant type was significantly lower than that in the early onset type $(\mathrm{P}<0.05)$ (Table 2$)$.

Table 2. P-gp and clinical type of ulcerative colitis.

\begin{tabular}{lcccc}
\hline Clinical type & $\mathrm{N}$ & Positive $(\mathrm{N})$ & Negative $(\mathrm{N})$ & Positive rate $(\%)$ \\
\hline Control & 35 & 11 & 24 & 31.4 \\
Early onset & 37 & 6 & 31 & $16.2^{\mathrm{a}}$ \\
Chronic relapsing & 33 & 5 & 28 & $15.2^{\mathrm{ab}}$ \\
Chronic persistent & 24 & 4 & 20 & $16.7^{\mathrm{ab}}$ \\
Acute fulminant & 15 & 1 & 14 & $6.7^{\text {ac }}$ \\
\hline
\end{tabular}

${ }^{\mathrm{a}} \mathrm{P}<0.05 v s$ control; ${ }^{\mathrm{b}} \mathrm{P}>0.05 v s$ early onset; ${ }^{\mathrm{c}} \mathrm{P}<0.05 v s$ early onset.

Disease activity in 76 cases was divided into mild, moderate, and severe. The P-gp expression rate in mild, moderate, and severe disease was significantly different from that in controls $(\mathrm{P}<0.05)$. No significant difference in the $\mathrm{P}$-gp expression rate was observed in moderate and severe disease compared to that in mild disease $(\mathrm{P}>0.05)$ (Table 3$)$.

Table 3. P-gp and the severity of active ulcerative colitis.

\begin{tabular}{lcccc}
\hline Severity & $\mathrm{N}$ & Positive $(\mathrm{N})$ & Negative $(\mathrm{N})$ & Positive rate $(\%)$ \\
\hline Control & 35 & 11 & 24 & 31.4 \\
Active mild & 40 & 6 & 34 & $15.0^{\mathrm{a}}$ \\
Active moderate & 24 & 3 & 21 & $12.5^{\mathrm{ab}}$ \\
Active severe & 12 & 2 & 10 & $16.7^{\mathrm{ab}}$ \\
\hline
\end{tabular}

${ }^{\mathrm{a}} \mathrm{P}<0.05 v s$ control; ${ }^{\mathrm{P}} \mathrm{P}>0.05 v s$ active mild.

\section{P-gp and the severity of UC}

\section{$P$-gp and clinical stages}

According to the clinical stage, UC cases were classified as being in remission or being active. The P-gp-positive expression rate in the remission and active stage was significantly lower than that in controls $(\mathrm{P}<0.05)$; however, no difference was observed between the active and remission stages $(\mathrm{P}<0.05)$ (Table 4$)$.

Table 4. Relationship between P-gp and clinical stage.
\begin{tabular}{lcccc}
\hline Stage & $\mathrm{N}$ & Positive (N) & Negative (N) & Positive rate (\%) \\
\hline Control & 35 & 11 & 24 & 31.4 \\
Remission & 33 & 5 & 28 & $15.2^{\text {a }}$ \\
Active & 76 & 13 & 63 & $17.1^{\text {ab }}$ \\
\hline
\end{tabular}

${ }^{\mathrm{a}} \mathrm{P}<0.05$ vs control; ${ }^{\mathrm{b}} \mathrm{P}>0.05$ vs remission. 


\section{Relationship between NO content, NOS activity, and P-gp in colonic mucosa}

Compared with normal controls, NO content and NOS activity in the colonic mucosa were significantly increased in active mild, moderate, and severe disease, as well as in early onset, chronic relapsing, chronic persistent, and acute fulminant disease $(\mathrm{P}<0.05)$. NO content and NOS activity in colonic mucosa increased significantly in active $v s$ remission cases, moderate and severe $v s$ mild cases, and in acute fulminant $v s$ early onset cases $(\mathrm{P}<0.05)$. NO content and NOS activity increased significantly in active moderate, active severe, early onset, chronic relapsing, chronic persistent, and acute fulminant disease in P-gp-positive patients compared with $\mathrm{P}$-gp-negative patients $(\mathrm{P}<0.05)$ (Tables 5 and 6, Figures 3 and 4).

\begin{tabular}{|c|c|c|c|}
\hline Group & $\mathrm{N}$ & P-gp-positive & P-gp-negative \\
\hline Control & 35 & $14.71 \pm 3.29$ & $12.65 \pm 2.52$ \\
\hline \multicolumn{4}{|l|}{ Clinical stage } \\
\hline Remission & 33 & $19.52 \pm 5.83$ & $15.27 \pm 3.96$ \\
\hline Active & 76 & $37.14 \pm 4.69^{\mathrm{ab}}$ & $26.28 \pm 4.92^{\mathrm{abf}}$ \\
\hline \multicolumn{4}{|l|}{ Severity } \\
\hline Mild & 40 & $25.73 \pm 6.28^{\mathrm{a}}$ & $22.28 \pm 5.14^{\mathrm{a}}$ \\
\hline Moderate & 24 & $41.16 \pm 5.19^{\mathrm{ac}}$ & $31.93 \pm 4.74^{\text {acf }}$ \\
\hline Severe & 12 & $47.53 \pm 9.82^{\mathrm{ac}}$ & $35.28 \pm 9.15^{\text {acf }}$ \\
\hline \multicolumn{4}{|l|}{ Clinical type } \\
\hline Early onset & 37 & $32.19 \pm 2.74^{\mathrm{a}}$ & $22.19 \pm 2.74^{\text {af }}$ \\
\hline Chronic relapsing & 33 & $36.52 \pm 8.35^{\mathrm{ac}}$ & $25.69 \pm 6.52^{\text {aef }}$ \\
\hline Chronic persistent & 24 & $31.52 \pm 4.61^{\mathrm{ac}}$ & $21.63 \pm 5.37^{\text {aef }}$ \\
\hline Acute fulminant & 15 & $56.17 \pm 8.72^{\text {ad }}$ & $41.29 \pm 9.44^{\text {adf }}$ \\
\hline
\end{tabular}

Table 6. Comparison of NOS activity in colonic mucosa (means $\pm \mathrm{SD})(\mathrm{U} / \mathrm{mg})$.

\begin{tabular}{|c|c|c|c|}
\hline Group & $\mathrm{N}$ & P-gp-positive & P-gp-negative \\
\hline Control & 35 & $8.65 \pm 2.47$ & $6.48 \pm 2.66$ \\
\hline \multicolumn{4}{|l|}{ Clinical stage } \\
\hline Remission & 33 & $11.38 \pm 3.16$ & $9.78 \pm 3.51$ \\
\hline Active & 76 & $19.27 \pm 4.51^{\mathrm{ab}}$ & $14.49 \pm 3.51^{\mathrm{abf}}$ \\
\hline \multicolumn{4}{|l|}{ Severity } \\
\hline Mild & 40 & $13.37 \pm 2.89^{\mathrm{a}}$ & $11.28 \pm 4.57^{\mathrm{a}}$ \\
\hline Moderate & 24 & $19.18 \pm 4.66^{\text {ac }}$ & $16.72 \pm 4.16^{\text {acf }}$ \\
\hline Severe & 12 & $28.15 \pm 5.37^{\mathrm{ac}}$ & $20.77 \pm 5.63^{\text {acf }}$ \\
\hline \multicolumn{4}{|l|}{ Clinical type } \\
\hline Early onset & 37 & $16.28 \pm 4.17^{\mathrm{a}}$ & $11.79 \pm 5.82^{\mathrm{af}}$ \\
\hline Chronic relapsing & 33 & $17.73 \pm 6.55^{\text {ae }}$ & $12.66 \pm 5.11^{\text {aef }}$ \\
\hline Chronic persistent & 24 & $16.96 \pm 5.18^{\mathrm{ac}}$ & $11.84 \pm 6.17^{\text {aef }}$ \\
\hline Acute fulminant & 15 & $21.59 \pm 7.62^{\text {ad }}$ & $16.49 \pm 3.62^{\text {adf }}$ \\
\hline
\end{tabular}

${ }^{\mathrm{a}} \mathrm{P}<0.05$ vs control; ${ }^{\mathrm{b}} \mathrm{P}<0.05$ vs remission; ${ }^{\mathrm{C}} \mathrm{P}<0.05$ vs mild; ${ }^{\mathrm{d}} \mathrm{P}<0.05$ vs early onset; ${ }^{\mathrm{e}} \mathrm{P}>0.05$ vs early onset; ${ }^{\mathrm{f}} \mathrm{P}<0.05$ vs $\mathrm{P}$-gp-positive.

\section{Relationship between serum IL-8 levels and P-gp}

Serum IL-8 levels were increased significantly in active mild, moderate, and severe disease, as well as in early onset, chronic persistent, and acute fulminant disease compared with the controls $(\mathrm{P}<0.05)$. Serum IL-8 increased significantly in active $v s$ remission, mod- 
erate and severe $v s$ mild, as well as in acute fulminant $v s$ early onset disease $(\mathrm{P}<0.05)$. In addition, IL-8 increased significantly in active, severe, early onset, chronic relapsing, chronic persistent, and acute fulminant disease in P-gp-positive patients compared with P-gp-negative patients $(\mathrm{P}<0.05)($ Table 7 , Figure 5).

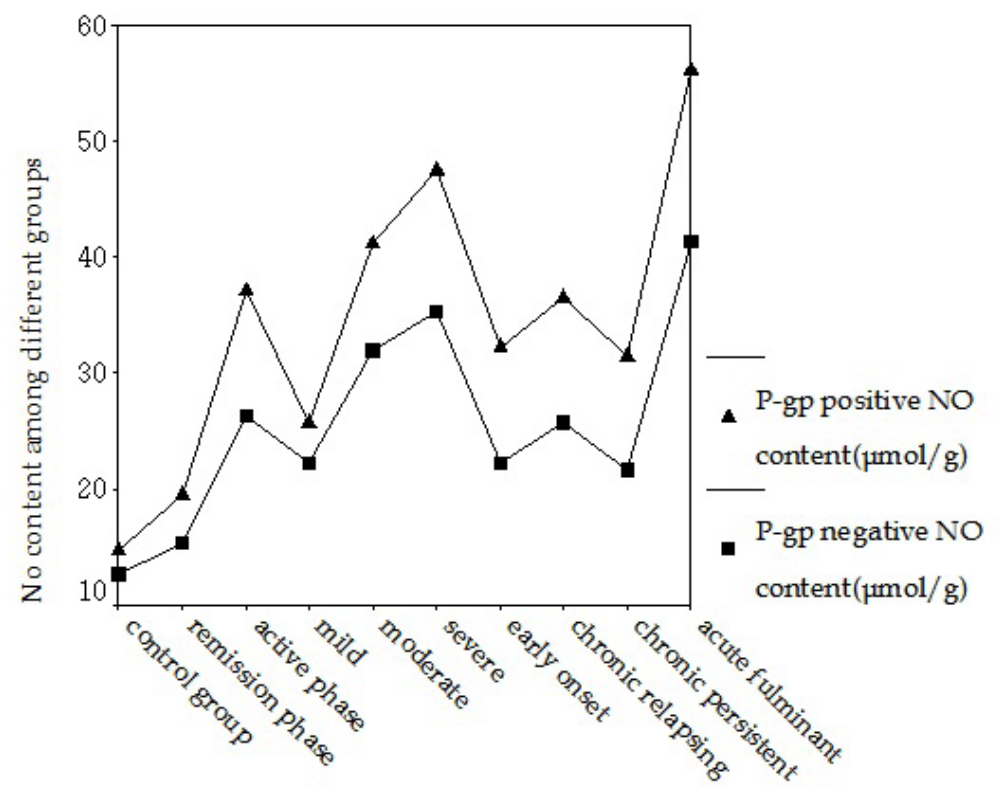

Figure 3. Comparison of NO content in colonic mucosa.

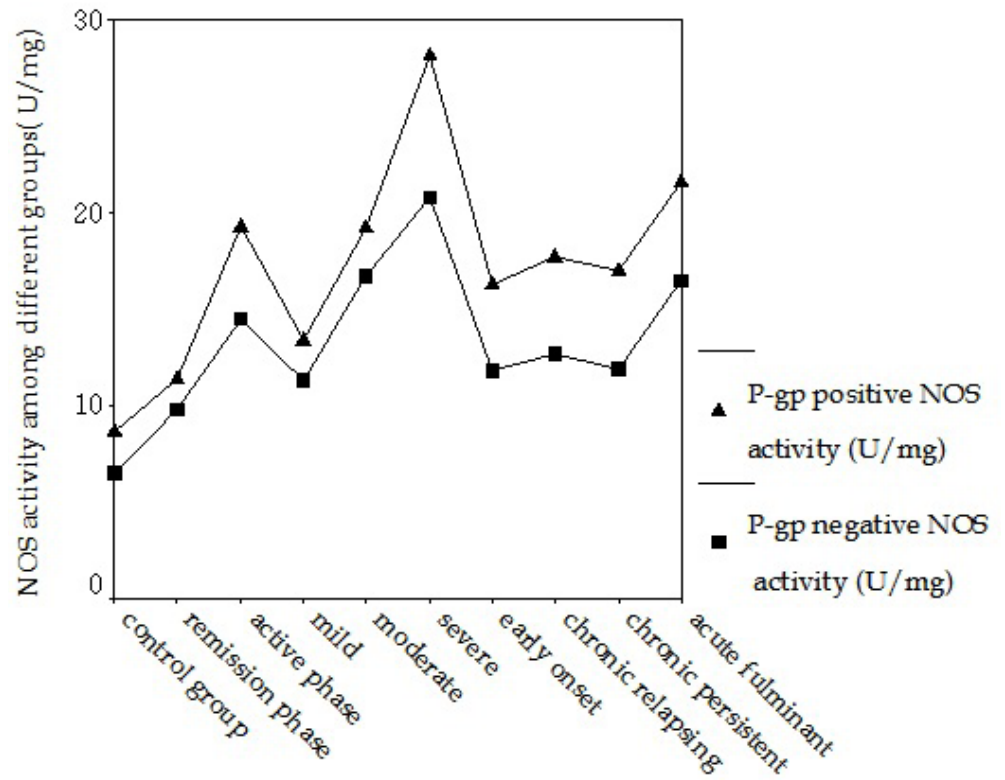

Figure 4. Comparison of NOS activity in colonic mucosa. 
Table 7. Comparison of IL-8 levels in the different groups (means $\pm \mathrm{SD})(\mathrm{pg} / \mathrm{mL})$.

\begin{tabular}{|c|c|c|c|c|}
\hline Group & $\mathrm{N}$ & P-gp-positive & P-gp-negative & $\mathrm{P}$ \\
\hline Control & 35 & $134.63 \pm 63.17$ & $116.85 \pm 43.71$ & \\
\hline \multicolumn{5}{|l|}{ Clinical stage } \\
\hline Remission & 33 & $286.58 \pm 57.82$ & $237.67 \pm 55.64$ & \\
\hline Active & 76 & $636.18 \pm 49.31^{\mathrm{ab}}$ & $499.14 \pm 47.69^{\mathrm{abf}}$ & $<0.05$ \\
\hline \multicolumn{5}{|l|}{ Severity } \\
\hline Mild & 40 & $437.29 \pm 67.58^{\mathrm{a}}$ & $396.38 \pm 66.28^{\mathrm{a}}$ & \\
\hline Moderate & 24 & $764.11 \pm 64.13^{\text {ac }}$ & $757.16 \pm 5.19^{\mathrm{ac}}$ & \\
\hline Severe & 12 & $978.57 \pm 34.24^{\mathrm{ac}}$ & $747.53 \pm 9.82^{\text {acf }}$ & $<0.05$ \\
\hline \multicolumn{5}{|l|}{ Clinical type } \\
\hline Early onset & 37 & $469.82 \pm 68.53^{\mathrm{a}}$ & $309.77 \pm 58.34^{\text {af }}$ & $<0.05$ \\
\hline Chronic relapsing & 33 & $502.34 \pm 40.89^{\mathrm{ac}}$ & $311.22 \pm 55.38^{\text {aef }}$ & $<0.05$ \\
\hline Chronic persistent & 24 & $491.42 \pm 65.28^{\mathrm{ac}}$ & $336.57 \pm 42.81^{\text {aef }}$ & $<0.05$ \\
\hline Acute fulminant & 15 & $984.19 \pm 68.74^{\text {ad }}$ & $751.54 \pm 80.12^{\text {adf }}$ & $<0.05$ \\
\hline
\end{tabular}

${ }^{\mathrm{a}} \mathrm{P}<0.05$ vs control; ${ }^{\mathrm{b}} \mathrm{P}<0.05$ vs remission; ${ }^{\mathrm{C}} \mathrm{P}<0.05$ vs mild; ${ }^{\mathrm{d}} \mathrm{P}<0.05$ vs early onset; ${ }^{\mathrm{P}} \mathrm{P}>0.05$ vs early onset; ${ }^{\mathrm{P}} \mathrm{P}$ $<0.05$ vs P-gp-positive.

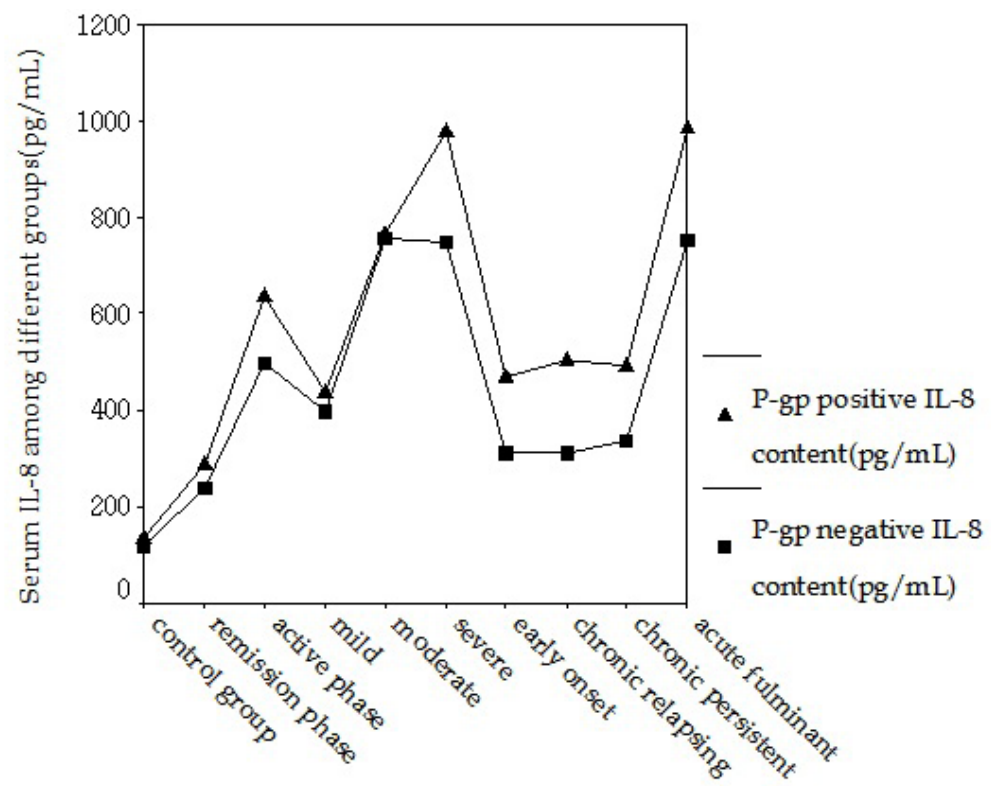

Figure 5. Comparison of serum IL-8 levels in different groups (pg/mL).

\section{Relationship between peripheral blood $\mathrm{CD}^{+}$and $\mathrm{CD}^{+} 5^{+} \mathrm{T}$ cell subsets and P-gp}

Peripheral blood $\mathrm{CD} 4^{+}$and $\mathrm{CD} 25^{+} \mathrm{T}$ cell subset percentages decreased significantly in active, mild, moderate, and severe disease, as well as in early onset, chronic persistent, and acute fulminant disease compared with in controls $(\mathrm{P}<0.05)$. Peripheral blood $\mathrm{CD} 4^{+}$and $\mathrm{CD} 25^{+} \mathrm{T}$ cell subset percentages decreased significantly in active $v s$ remission, moderate and severe $v s$ mild, as well as in acute fulminant $v s$ early onset disease $(\mathrm{P}<0.05)$. Peripheral blood $\mathrm{CD}^{+}$and $\mathrm{CD} 25^{+} \mathrm{T}$ cell subset percentages decreased significantly in active, severe, early onset, chronic relapsing, chronic persistent, and acute fulminant disease in P-gp-positive patients compared with P-gp-negative patients $(\mathrm{P}<0.05)$ (Table 8, Figure 6). 
Table 8. Comparison of peripheral blood $\mathrm{CD} 4^{+}$and $\mathrm{CD} 25^{+} \mathrm{T}$ cell subset percentage (means $\left.\pm \mathrm{SD}\right)$.

\begin{tabular}{|c|c|c|c|c|}
\hline Group & $\mathrm{N}$ & P-gp-positive & P-gp-negative & $\mathrm{P}$ \\
\hline Control & 35 & $0.84 \pm 0.27$ & $0.96 \pm 0.19$ & \\
\hline \multicolumn{5}{|l|}{ Clinical stage } \\
\hline Remission & 33 & $0.75 \pm 0.12$ & $0.87 \pm 0.14$ & \\
\hline Active & 76 & $0.09 \pm 0.27^{\mathrm{ab}}$ & $0.44 \pm 0.43^{\mathrm{abf}}$ & $<0.05$ \\
\hline \multicolumn{5}{|l|}{ Severity } \\
\hline Mild & 40 & $0.29 \pm 0.38^{\mathrm{a}}$ & $0.34 \pm 0.28^{\mathrm{a}}$ & \\
\hline Moderate & 24 & $0.18 \pm 0.31^{\text {ac }}$ & $0.20 \pm 0.35^{\mathrm{ac}}$ & \\
\hline Severe & 12 & $0.05 \pm 0.26^{\mathrm{ac}}$ & $0.19 \pm 0.82^{\text {acf }}$ & $<0.05$ \\
\hline \multicolumn{5}{|l|}{ Clinical type } \\
\hline Early onset & 37 & $0.15 \pm 0.51^{\mathrm{a}}$ & $0.36 \pm 0.34^{\mathrm{af}}$ & $<0.05$ \\
\hline Chronic relapsing & 33 & $0.11 \pm 0.34^{\text {ae }}$ & $0.32 \pm 0.31^{\text {aef }}$ & $<0.05$ \\
\hline Chronic persistent & 24 & $0.17 \pm 0.23^{\text {ae }}$ & $0.34 \pm 0.57^{\text {aef }}$ & $<0.05$ \\
\hline Acute fulminant & 15 & $0.03 \pm 0.25^{\mathrm{ad}}$ & $0.17 \pm 0.32^{\text {adf }}$ & $<0.05$ \\
\hline
\end{tabular}

${ }^{\mathrm{a}} \mathrm{P}<0.05$ vs control; ${ }^{\mathrm{b}} \mathrm{P}<0.05$ vs remission; ${ }^{\mathrm{C}} \mathrm{P}<0.05$ vs mild; ${ }^{\mathrm{d}} \mathrm{P}<0.05$ vs early onset; ${ }^{\mathrm{e}} \mathrm{P}>0.05$ vs early onset; ${ }^{\mathrm{f}} \mathrm{P}<0.05$ vs $\mathrm{P}$-gp-positive.

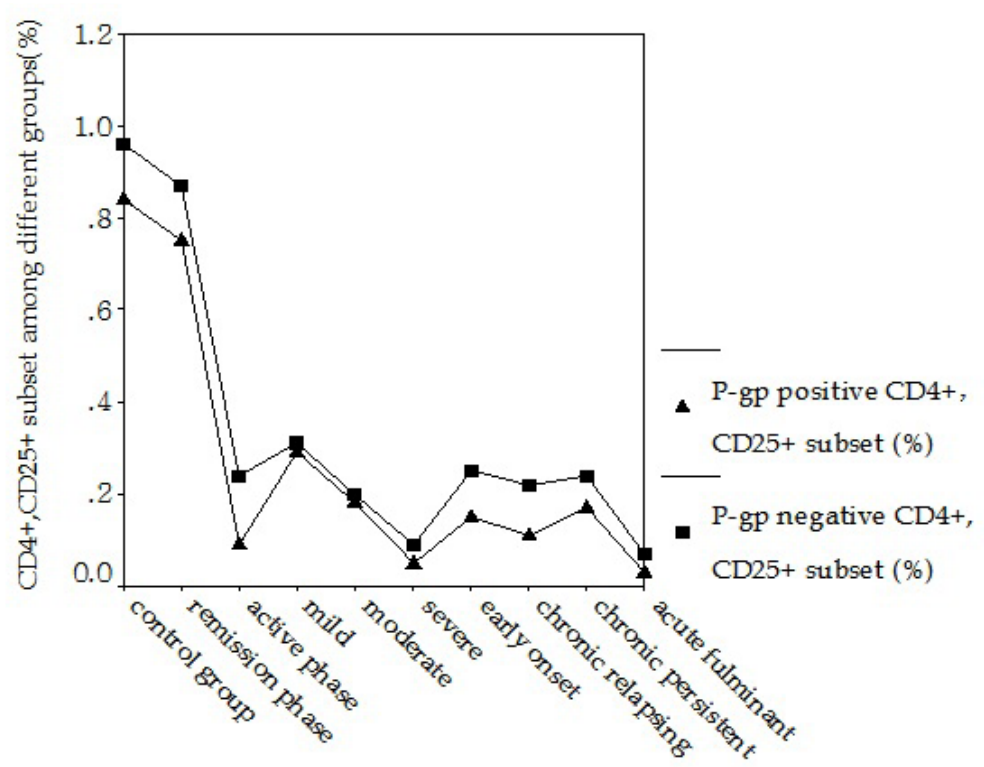

Figure 6. Comparison of peripheral blood $\mathrm{CD}^{+}$and $\mathrm{CD} 25^{+}$cell subset $(\%)$.

\section{DISCUSSION}

In this study, we found that the expression of P-gp in patients with UC before and after $6,12,18$, and 24 months of treatment was lower than that in the control group. There was no difference in P-gp expression before treatment and 6 months after treatment; however, the rates of P-gp-positive patients after 12,18, and 24 months of treatment were significantly different from those before treatment. These findings indicate that regardless of the type of UC, expression of the MDR1 product, $\mathrm{P}$-gp, is lower in UC patients than in normal healthy individuals. These findings also demonstrate that P-gp expression is not related to the duration of disease; as disease duration increased, P-gp became lower. It is unclear why P-gp expression was significantly lower in patients with acute fulminant UC. 
Multidrug resistance is the most important cellular defense mechanism of tumor cells to avoid attack by chemotherapeutic agents (Gutmann et al., 2008), and multidrug resistance was initially identified in the study of drug resistance in tumor cells. However, P-gp is present not only in tumor cells, but also in normal cells (Fedier et al., 2007), and the results of this study showed that the multidrug resistance gene was present in normal controls, indicating intrinsic multidrug resistance.

Expression of the drug resistance gene was significantly lower in patients with UC before treatment and during early treatment than in controls. As disease duration increased, the drug resistance gene expression rate decreased; lowered P-gp expression can weaken the intestinal protective effect and increase disease activity.

P-gp expression rates in remission or active UC, regardless of disease severity, were significantly reduced compared with normal controls, and no differences were observed between remission and active disease or between patients with different disease severity. Therefore, irrespective of whether UC was in remission or active, P-gp expression was lower than that in normal healthy individuals. Similar results were demonstrated for the positive expression of P-gp in UC; however, this was not related to disease severity or active or remission status. The positive expression rates in all lesions were significantly different compared with normal controls. However, no differences were observed among lesions in different locations, i.e., straight sigmoid colon lesions, left colon lesions, extensive colon lesions, and rectal lesions. No significant difference in the P-gp expression rate was observed in UC patients without $v s$ with extra-intestinal lesions.

These results suggest that expression of the MDR1 product, $\mathrm{P}$-gp, in UC is related to disease occurrence. Patients with UC may have inherent changes in drug resistance gene expression; the disease may occur with decreased P-gp expression and the extent of disease and extra-intestinal manifestations are irrelevant.

Studies examining autoimmune diseases and organ transplantation found that P-gp is the most important factor affecting the efficacy of corticosteroids, cyclosporin A, FK506, cyclophosphamide, azathioprine, and other immunosuppressive agents (Verbon et al., 2002). The high expression of P-gp in the peripheral blood lymphocytes of patients with systemic lupus erythematosus resulted indecreased lymphocyte glucocorticoid levels, steroid-resistance, and reduced efficacy (Hibi et al., 2003). A study by Wasilewska et al. (2007) also showed that steroid-resistance or -dependence in children with nephrotic syndrome was related to P-gp expression in peripheral lymphocytes.

The relationship between P-gp expression and the immune status of patients with UC in this study showed the following results: compared with normal controls, NO content and NOS activity in the colonic mucosa were significantly increased in active, active mild, moderate, and severe disease, as well as early onset, chronic relapsing, chronic persistent, and acute fulminant disease. NO content and NOS activity increased significantly in active $v s$ remission, moderate or severe $v s$ mild, and acute fulminant $v s$ early onset disease, respectively. In addition, NO content and NOS activity were significantly increased in P-gp-positive patients compared to P-pg-negative patients with active, moderate, severe, early onset, chronic relapsing, chronic persistent, and acute fulminant UC. These results indicate that NO content and NOS activity in the colonic mucosa was significantly increased in UC independently of disease severity. In patients with high P-gp expression, increases in NO content and NOS activity were even more significant. 
Increases in NO content and NOS activity were more significant in UC patients with high P-pg expression; these values increased with disease duration and severity. This may have resulted from recognition of the drug as a foreign body; therefore, P-gp plays a very important role in drug absorption and distribution in the body.

A previous study found that various drugs are substrates of P-gp and that P-gp substrates in the cytoplasm accumulates to high concentrations in the phospholipid bilayer and are then transferred to the substrate-binding site. ATP hydrolysis occurs at ATP-binding sites as an energy source, and the drug is then discharged into the extracellular region. As a result, P-gp reduces the oral bioavailability of substrates and MDR tumor cell toxicity, limiting the effects of the drugs (Hartz et al., 2004). Alternatively, this may also result from both internal drug resistance changes in UC and the development of inflammation (Salas et al., 2002).

Recent studies showed that endogenous NO is involved in the gastrointestinal mucosal barrier and the inflammatory process. NO is closely related with colonic disease and an NOS-inducer exists in UC. Increased iNOS and NO are characteristic of UC, and when subjected to certain cytokines, pathogenic microorganisms, and other stimuli for a few hours, a large amount of iNOS is generated, which leads to increased NO synthesis (Seril et al., 2007).

As a result of drug resistance, UC becomes refractory to treatment, leading to the spread of inflammation and disease progression. This, in turn, significantly increases NO content and NOS activity.

NO produced by catalytic arginine and structural NOS is thought to protect the intestinal mucosa, while NO produced by iNOS is toxic and increases inflammation. Decreased production of NO results in smooth muscle contraction, which is likely the most important factor causing bowel movement disorders and mucosal damage, indicating that, under certain circumstances, iNOS has a protective effect. Therefore, a small amount of NO is physiologically protective, while a large amount of NO increases inflammation and causes damage (Guihot et al., 2000).

IL-8 is primarily produced by mononuclear macrophages and endothelial cells when stimulated by other cytokines. Its main biological role is the chemotaxis of eosinophils, neutrophils, basophils, and T cells. It also promotes neutrophil lysosomal enzyme activity and phagocytosis, as well as induces neutrophil degranulation. IL-8 is a powerful leukocyte chemotactic factor and activator and an effective inflammatory chemokine. Subcutaneous injection of IL-8 into animals results in a large local accumulation of neutrophils and histopathological changes of acute inflammation (Sangfelt et al., 2002). The inflammatory response induced by IL-1, tumor necrosis factor (TNF)- $\alpha$, and IL- 6 is considered to be mainly mediated by chemokines, and IL-8 is one of the most important chemokines. This study demonstrated that IL-8 was significantly increased in active, mild, moderate, severe, early onset, chronic relapsing, chronic persistent, and acute fulminant UC compared to controls $(\mathrm{P}<0.05)$. Serum IL- 8 levels increased in active $v s$ remission, moderate and severe $v s$ mild, and acute fulminant $v s$ early onset disease $(\mathrm{P}<0.05)$. In addition, serum IL-8 levels significantly increased in active, severe, and acute fulminant UC in P-gp-positive patients compared to in P-gp-negative patients $(\mathrm{P}<0.05)$. Higher $\mathrm{P}$-gp expression in UC was correlated with higher IL-8 levels, which was more obvious as the duration and severity of UC increased. This may be either the result of drug treatment or the result of an interaction between the internal resistance of UC and the development of inflammation. Fan et al. (2009) investigated the relationship between inflammatory bowel disease activity and serum IL- 8 and TNF- $\alpha$ levels and showed that serum IL-8 and TNF- $\alpha$ increased in UC patients compared to those in remission and normal controls. Increased IL- 8 and TNF- $\alpha$ contribute to mucosal inflammatory damage. Drug resistance in 
UC increases inflammation and significantly increases NO, NOS, and IL-8. P-gp is an important physiological transporter protein, and is mainly involved in normal tissue detoxification, removal of toxic substances in vivo, hormone secretion, transport of certain substances, and the protection of normal tissue cells against damage caused by exogenous toxins. Drugs are considered by the body to be foreign substances; thus, P-gp also plays a very important role in drug absorption and distribution. P-gp can discharge drugs from the cell; therefore, P-gp can reduce the oral bioavailability of substrate drugs (Ufer et al., 2009).

Various studies have suggested that abnormal immune and inflammatory responses in the intestinal mucosa play an important role in the pathogenesis of $\mathrm{UC}$, and T cells are the primary immune cells involved in these responses. UC is an autoimmune disease involving immune response, genetic, environmental, and other factors. T cells are key immune cells in normal intestinal mucosal immune responses (Sheikh et al., 2008). T cells exert their effect mainly through $\mathrm{T}$ cell antigen receptor-mediated antigen recognition, activation, cytotoxicity, cytokine production, and secretion to protect the intestinal mucosa, remove damaged epithelial cells, resist the invasion by foreign antigens, and balance the intestinal environment so that the intestine can function normally. If there is an imbalance in the intestinal mucosal immunity and inflammation, this will inevitably lead to intestinal mucosal damage and colitis.

The results of this study showed that the peripheral $\mathrm{CD} 4^{+}$and $\mathrm{CD} 25^{+}$subset percentages significantly decreased in active, mild, moderate, and severe disease, early onset, chronic relapsing, chronic persistent, and acute fulminant UC compared to normal controls. The peripheral $\mathrm{CD}^{+}$and $\mathrm{CD} 25^{+}$subset percentage decreased significantly in active $v s$ remission, moderate and severe $v s$ mild, and acute fulminant $v s$ early onset disease $(\mathrm{P}<0.05)$. The peripheral $\mathrm{CD}^{+}$and $\mathrm{CD} 25^{+}$subset percentage also decreased significantly in active, severe, and acute fulminant disease in P-gp-positive patients compared to P-gp-negative patients.

In normal mucosal tissues, effector $\mathrm{T}$ cells and regulatory $\mathrm{T}$ cells are in a state of dynamic equilibrium to maintain intestinal mucosa homeostasis and immune system stability. If there are too many effector $\mathrm{T}$ cells or enhanced immunogenicity, the effect of effector $\mathrm{T}$ cells will surpass that of regulatory $\mathrm{T}$ cells; if there is a decrease in the number of regulatory $\mathrm{T}$ cells or functional abnormalities, both can upset the balance between the two, leading to mucosal injury and inflammatory bowel disease (Sumida et al., 2008). Among the peripheral T-cell subsets, $\mathrm{CD}^{+} \mathrm{T}$ cells have been identified as the main effector cells leading to intestinal inflammation and are the main cell type found in mucosal tissue infiltration in all colitis models. In some studies, inflammation was improved after removal of $\mathrm{CD}^{+} \mathrm{T}$ cells from the body, and specific expression of the forkhead/winged helix transcription factor in $\mathrm{CD} 4^{+}$ and CD25+regulatory T cells can effectively prevent UC (Sitohy et al., 2008). Regulatory T cells include Trl, which secretes high levels of IL-10, and Th3, which mainly secretes TGF- $\beta$. In addition, forkhead/winged helix transcription factoris specifically expressed in $\mathrm{CD}^{+}$and $\mathrm{CD} 25^{+}$regulatory T-cells. $\mathrm{CD} 4{ }^{+}$and $\mathrm{CD} 25^{+}$regulatory T-cells play an important role in the development of Th3 for Trl. Regulatory T cells differ from helper T cells; Thl and Th2 are T cells with immune regulation function and play an important regulatory role in a variety of autoimmune diseases.

Regulatory T cells were first reported by Sakaguchi et al. (2004). Direct cell contact and the release of TGF- $\beta$, IL-10, and other cytokines can suppress autoreactive T cells and reduce Th1 functions, which is important in immune tolerance and maintaining the balance of immune function.

This study also confirmed that immune injury plays a very important role in the patho- 
genesis of UC. This results because the entire immune system, including NO content and NOS activity, significantly increases inflammation. The inflammatory effect of IL- 8 and CD4 ${ }^{+}$and $\mathrm{CD} 25^{+}$regulatory $\mathrm{T}$ cells on immune and inflammatory responses in the intestinal mucosa was also confirmed. Multidrug resistance gene overexpression in UC may result from either intrinsic lesion development or drug-induced secondary resistance. UC becomes refractory because of drug resistance with progression of inflammatory lesions. As a result, NO content and NOS activity increase, and the inflammatory effects of IL- 8 , as well as the effect of CD4 ${ }^{+}$ and $\mathrm{CD} 25^{+}$regulatory $\mathrm{T}$ cells in the immune and inflammatory responses in the intestinal mucosa are significantly enhanced. This multi-drug resistance gene overexpression is related to the duration and inflammatory activity of UC.

\section{CONCLUSION}

Expression of the multidrug resistance gene product, P-gp, is closely related to the duration of $\mathrm{UC}$; the longer the duration of $\mathrm{UC}$, the lower the P-gp expression. Expression of the multidrug resistance gene and its product, $\mathrm{P}$-gp, is found in normal colon tissue and is closely related to UC. Decreased expression of the multidrug resistance gene and P-gp may cause UC. In patients expressing the multidrug resistance gene and P-gp, immune injury plays a more important role in the pathogenesis of UC.

\section{ACKNOWLEDGMENTS}

Research supported by the Scientific Research Foundation of the Doctor (\#20110102).

\section{REFERENCES}

Arnold C, Moradpour D and Blum HE (1998). Tuberculosis colitis mimicking Crohn's disease. Am. J. Gastroenterol. 93 : 2294-2296.

Asari A, Kanemitsu T and Kurihara H (2010). Oral administration of high molecular weight hyaluronan (900 kDa) controls immune system via Toll-like receptor 4 in the intestinal epithelium. J. Biol. Chem. 285: 24751-24758.

Chandran P, Satthapom S, Robins A and Eremin O (2003). Inflammatory bowel disease: dysfunction of GALT and gut bacterial flora (II). Surgeon 1: 125-136.

Dommels YE, Butts CA, Zhu S, Davy M, et al. (2007). Characterization of intestinal inflammation and identification of related gene expression changes in mdr1a(-/-) mice. Genes Nutr. 2: 209-223.

Fan H, Shen L, Tang Q, Xiong P, et al. (2009). Effect of Wumeiwan on cytokines TNF-alpha, IL-6, IL-8, IL-10 and expression of NF-kappaBp65 in rats with ulcerative colitis. J. Huazhong Univ. Sci. Technol. Med. Sci. 29: 650-654.

Farrell RJ and Kelleher D (2003). Glucocorticoid resistance in inflammatory bowel disease. J. Endocrinol. 178: 339-346.

Fedier A, Dedes KJ, Imesch P, Von Bueren AO, et al. (2007). The histone deacetylase inhibitors suberoylanilide hydroxamic (Vorinostat) and valproic acid induce irreversible and MDR1-independent resistance in human colon cancer cells. Int. J. Oncol. 31: 633-641.

Forchielli ML and Walker WA (2005). The role of gut-associated lymphoid tissues and mucosal defence. Br. J. Nutr. 93: S41-S48.

Guihot G, Guimbaud R, Bertrand V, Narcy-Lambare B, et al. (2000). Inducible nitric oxide synthase activity in colon biopsies from inflammatory areas: correlation with inflammation intensity in patients with ulcerative colitis but not with Crohn's disease. Amino Acids 18: 229-237.

Gutmann H, Hruz P, Zimmermann C, Straumann A, et al. (2008). Breast cancer resistance protein and P-glycoprotein expression in patients with newly diagnosed and therapy-refractory ulcerative colitis compared with healthy controls. Digestion 78: 154-162.

Hartz AM, Bauer B, Fricker G and Miller DS (2004). Rapid regulation of P-glycoprotein at the blood-brain barrier by endothelin-1. Mol. Pharmacol. 6: 387-394. 
Hibi T, Naganuma M, Kitahora T, Kinjyo F, et al. (2003). Low-dose azathioprine is effective and safe for maintenance of remission in patients with ulcerative colitis. J. Gastroenterol. 38: 740-746.

Mendoza JL, Urcelay E, Lana R, Martín MC, et al. (2007). MDR1 polymorphisms and response to azathioprine therapy in patients with Crohn's disease. Inflamm. Bowel Dis. 13: 580-595.

Potocnik U, Ferkolj I, Glavac D and Dean M (2004). Polymorphisms in multidrug resistance 1 (MDR1) gene are associated with refractory Crohn disease and ulcerative colitis. Genes Immun. 5: 530-539.

Sakaguchi E, Sakaida I and Okita K (2004). Th1/Th2 balance in HCV-related liver cirrhosis and the effect of TGF-beta on Th1 response: possible implications for the development of hepatoma. Nihon. Rinsho. 62 (Suppl 7): 175-178.

Salas A, Gironella M, Salas A, Soriano A, et al. (2002). Nitric oxide supplementation ameliorates dextran sulfate sodiuminduced colitis in mice. Lab. Invest. 82: 597-607.

Sangfelt P, Carlson M, Thörn M, Xu S, et al. (2002). Local release of human neutrophil lipocalin (HNL), IL-8, and TNFalpha is decreased as response to topical prednisolone treatment in distal ulcerative colitis and proctitis. Dig. Dis. Sci. 47: 2064-2069.

Saverymuttu SH, Hodgson HJ, Chadwick VS and Pepys MB (1986). Differing acute phase responses in Crohn's disease and ulcerative colitis. Gut 27: 809-813.

Seril DN, Liao J and Yang GY (2007). Colorectal carcinoma development in inducible nitric oxide synthase-deficient mice with dextran sulfate sodium-induced ulcerative colitis. Mol. Carcinog. 46: 341-353.

Sheikh S, Uno J, Matsuoka K and Plevy S (2008). Abnormal mucosal immune response to altered bacterial flora following restorative proctocolectomy in patients with ulcerative colitis: serologic measures, immunogenetics, and clinical correlations. Clin. Immunol. 127: 270-279.

Sitohy B, Hammarström S, Danielsson A and Hammarström ML (2008). Basal lymphoid aggregates in ulcerative colitis colon: a site for regulatory T cell action. Clin. Exp. Immunol. 151: 326-333.

Spahn TW and Kucharzlk T (2004). Modulating the intestinal immune system: the role of lymphotoxin and GALT organs. Gut 53: 456-465.

Sumida Y, Nakamura K, Kanayama K, Akiho H, et al. (2008). Preparation of functionally preserved CD4 $4^{+} D 25^{+}$high regulatory $\mathrm{T}$ cells from leukapheresis products from ulcerative colitis patients, applicable to regulatory T-cell transfer therapy. Cytotherapy 10: 698-710.

Thompson-Chagoyán OC, Maldonado J and Gil A (2005). Aetiology of inflammatory bowel disease (IBD): role of intestinal microbiota and gut-associated lymphoid tissue immune response. Clin. Nutr. 24: 339-352.

Ufer M, Häsler R, Jacobs G, Haenisch S, et al. (2009). Decreased sigmoidal ABCB1 (P-glycoprotein) expression in ulcerative colitis is associated with disease activity. Pharmacogenomics 10: 1941-1953.

Verbon A, Leemans JC, Weijer S, Florquin S, et al. (2002). Mice lacking the multidrug resistance protein 1 have a transiently impaired immune response during tuberculosis. Clin. Exp. Immunol. 130: 32-36.

Wasilewska A, Zalewski G, Chyczewski L and Zoch-Zwierz W (2007). MDR-1 gene polymorphisms and clinical course of steroid-responsive nephrotic syndrome in children. Pediatr. Nephrol. 22: 44-51. 